Division of

Epidemiology, Istituto

Nazionale per lo

Studio e la Cura dei

Tumori, Milan, Italy

G Gatta

M Sant

F Berrino

Laboratory of

Epidemiology and

Biostatistics, Istituto

Superiore di Sanità,

Rome, Italy

R Capocaccia

Thames Cancer

Registry, UK

C M J Bell

Eindhoven Cancer

Registry, Eindhoven,

Netherlands

J W W Coebergh

Rotterdam Cancer

Registry, Rotterdam,

Netherlands

R A M Damhuis

Côte d'Or Cancer

Registry, University of

Dijon, France

J Faivre

Granada Cancer

Registry, EASP,

Granada, Spain

C Martinez-Garcia

Department of

Oncology, Jagiellanian

Unversity, Krakow,

Poland

J Pawlega

Modena Colorectal

Cancer Registry,

Università di Modena,

Italy

M Ponz de Leon

Calvados Digestive

Cancer Registry, Caen,

France

D Pottier

Somme Cancer

Registry, France

N Raverdy

Merseyside and Cheshire Cancer Registry, Liverpool,

UK

E M I Williams

Correspondence to:

Dr G Gatta, Divisione di

Epidemiologia, Istituto

Nazionale per la Cura e lo

Studio dei Tumori, Via

Venezian, 1, 20133 Milano,

Italy. Email:

gatta@istitutotumori.mi.it

Accepted for publication 4 April 2000

\title{
Understanding variations in survival for colorectal cancer in Europe: a EUROCARE high resolution study
}

G Gatta, R Capocaccia, M Sant, C M J Bell, J W W Coebergh, R A M Damhuis, J Faivre, C Martinez-Garcia, J Pawlega, M Ponz de Leon, D Pottier, N Raverdy, E M I Williams, F Berrino

\begin{abstract}
Background-Marked differences in population based survival across Europe were found for colorectal cancers diagnosed in 1985-1989.
\end{abstract}

Aims-To understand the reasons for these differences in survival in a new analysis of colorectal cancers diagnosed between 1988 and 1991.

Subjects-A total of 2720 patients with adenocarcinoma of the large bowel from 11 European cancer registries (CRs).

Methods-We obtained information on stage at diagnosis, diagnostic determinants, and surgical treatment (not routinely collected by CRs) and analysed the data in relation to three year observed survival, calculating relative risks (RRs) of death and adjusting for age, sex, site, stage, and determinants of stage.

Results-Three year observed survival rates ranged from $25 \%$ (Cracow) to $59 \%$ (Modena), and were low in the Thames area (UK) $(38 \%)$. Survival rates between registries for "resected" patients varied less than those for all patients. When age, sex, and site were considered, $R$ Rs ranged from 0.7 (95\% confidence intervals (CI) 0.6-0.9) (Modena) to 2.3 (95\% CI 1.9-2.9) (Cracow). After further adjustment by stage, between registry $R R$ variation was between 0.8 (95\% CI 0.6-0.9) and $1.8(95 \%$ CI 1.5-2.2). Inter-registry RR differences were slightly reduced when the determinants of stage (number of nodes examined and liver imaging) were included in the model. The reduction was marked for the UK registries.

Conclusions-The wide differences across Europe in colorectal cancer survival depend to a large extent on differences in stage at diagnosis. There are wide variations in diagnostic and surgical practices. There was a twofold range in the risk of death from colorectal cancer even after adjustment for surgery and disease stage. (Gut 2000;47:533-538)

Keywords: colorectal cancer; population based cancer registries; stage at diagnosis; survival; surgery; Europe

The EUROCARE II study ${ }^{1}$ on cancer survival in Europe, using data from population based cancer registries (CRs), found that survival for patients with colorectal cancer diagnosed in
1985-1989 varied markedly. Five year relative survival - that is, the ratio of observed survival in cancer patients to the expected survival of the general population-was greater than $45 \%$ in CRs from Switzerland, France, Italy, Spain, the Netherlands, Sweden, and Finland but less than 35\% in Slovenia and Poland; in England, survival was intermediate $(41 \%)$. The proportions of patients who underwent surgical resection also varied widely across Europe, ranging from greater than $85 \%$ in Switzerland, the Netherlands, and France to less than $60 \%$ in Estonia and Poland. ${ }^{2}$ Most of the differences in survival between countries for colorectal cancers were confined to the first six months after diagnosis, while five year survival, conditional on surviving the first six months, was much more homogeneous. This pattern suggested that a large portion of the survival differences between countries was due to variation in the proportion of very advanced cases at diagnosis. $^{3}$

In most European countries, survival of patients with colorectal cancer is increasing: the disease related relative excess risk of death (RR) decreased from 1978-1980 to 19871989 by an average of $20 \%{ }^{4}$

Longer survival is due to better treatment, earlier diagnosis, or both. These two factors can be distinguished by determining if survival is improving in stage specific analyses or only in the total series of cases. However, with the development of new diagnostic techniques, a fraction of cancers that would previously have been classified as localised are found to be at a more advanced stage. The shifting of such cases from earlier to more advanced stages results in improved survival (relative to previous data) in both categories. This is the so-called stage migration phenomenon. ${ }^{5}$ Furthermore, new and improved diagnostic techniques do not become available at the same time throughout Europe or within a single country and may not be applied universally in clinical practice. These phenomena have an important confounding effect on stage specific survival comparisons between populations and must be considered when attempting to interpret differences in survival between areas and countries.

Information on the diagnostic procedures used for defining disease stage is rarely available to population based CRs. Hence the

Abbreviations used in this paper: CRs, cancer registries; RR, relative risk. 
Table 1 Colorectal cancer cases by registry, period of diagnosis, sex, age, and site. EUROCARE high resolution study on colorectal cancer

\begin{tabular}{llcllll}
\hline Country & Registry & $\begin{array}{c}\text { Total } \\
\text { cases }\end{array}$ & $\begin{array}{l}\text { Period of } \\
\text { study }\end{array}$ & $\begin{array}{l}\text { Males } \\
(\%)\end{array}$ & $\begin{array}{l}\text { Age 75+ } \\
(\%)\end{array}$ & $\begin{array}{l}\text { Colon } \\
(\%)\end{array}$ \\
\hline Italy & Varese & 445 & 90 & 53 & 37 & 62 \\
France & Modena & 306 & $90-91$ & 52 & 32 & 65 \\
& Calvados & 262 & 90 & 47 & 40 & 52 \\
\multirow{5}{*}{ The Netherlands } & Somme & 228 & 90 & 60 & 38 & 64 \\
\multirow{2}{*}{ Spain } & Côte d'Or & 237 & 90 & 54 & 46 & 66 \\
UK & Rotterdam & 202 & 90 & 54 & 40 & 63 \\
\multirow{2}{*}{ Poland } & Eindhoven & 256 & 91 & 52 & 33 & 68 \\
Total & Granada & 173 & 90 & 51 & 31 & 54 \\
& Mersey & 207 & 90 & 48 & 47 & 58 \\
& Thames & 176 & 90 & 47 & 43 & 55 \\
& Cracow & 228 & $88-89$ & 42 & 21 & 52 \\
& All registries & 2720 & $88-91$ & 51 & 37 & 60 \\
\hline
\end{tabular}

aim of this study was to obtain information on disease stage, staging procedures, and treatments for a representative sample of cases of colorectal cancer diagnosed in 1990 in 11 European populations and examine the influence of these factors on survival.

\section{Patients and methods}

Eleven population based CRs, from Italy, France, Spain, the Netherlands, England, and Poland contributed data (table 1). Each registry was asked to provide information on a representative sample of consecutive colorectal cancer cases incident in 1990 over a period of a few months to a few years (or over the period 1988-1991, if necessary, to reach the minimum sample size of 200 cases). All cases had been followed for at least three years. Details of the diagnostic and treatment procedures applied to each patient were obtained from the original clinical records and information abstracted onto a standard form. Stage was specified either by the TNM system or Dukes' classification $^{6}$; the most commonly used was Dukes'. When only TNM stage was available, TNM categories were converted to Dukes' stages. Whenever stage was not explicitly indicated in the clinical notes, trained recorders were engaged by the registries to reconstruct, where possible, the Dukes' categories on the basis of pathological, imaging, and surgical information contained in the records. This occurred in $45 \%$ of all cases considered in this study.

Two primary examinations, ultrasonic or CT scan of the liver, and total number of lymph nodes examined by the pathologist were also investigated as separate determinants of stage. It is generally considered that at least 12 lymph nodes should be examined for accurate staging. ${ }^{7}$

Detailed information on type of surgery was also abstracted from the clinical records. For the purposes of this study, resected patients were defined as those who underwent surgery to remove the primary bowel tumour, whether or not it was judged radical. Any bowel surgery that did not aim to remove the primary tumour was defined as palliative.

A total of 2720 cases were analysed. Only patients with primary malignant invasive adenocarcinomas were considered; in situ cancers, carcinoids and non-epithelial tumours were excluded. Cases known to the registries through death certificate only or discovered incidentally at autopsy were also excluded. Exclusion of these cases caused the sample size to fall below 200 cases for the registries of Granada (Spain) and Thames (UK), resulting in possible overestimation of survival rates in these two CRs.

Table 1 shows the distribution of cases by sex, age, and cancer site according to the registry. The proportion of males ranged from $42 \%$ (Cracow) to $60 \%$ (Somme). Thirty seven per cent of patients were more than 74 years of age, varying between $21 \%$ (Cracow) and $47 \%$ (Mersey). There were more colon than rectal cancer cases, with the range for the former of $52-68 \%$ according to registry.

Observed survival was analysed using the actuarial method. ${ }^{9}$ Cox proportional hazard models ${ }^{10}$ were used to compare hazard rates between registries, taking into account the different distributions of age, sex, site (colon/ rectum), stage, diagnostic determinants, and surgical treatment. Cox model analysis stratified by registry and multiple regression analysis

Table 2 Three year observed survival (3 y surv) and distribution of cases by Dukes'stage and stage determinants, according to registry. EUROCARE high resolution study on colorectal cancer

\begin{tabular}{|c|c|c|c|c|c|c|c|}
\hline \multirow[b]{3}{*}{ Registry (No of cases) } & \multirow[b]{3}{*}{3 y surv (\%) } & \multicolumn{6}{|c|}{$\%$ Distribution of } \\
\hline & & \multicolumn{4}{|c|}{ Dukes'stage ${ }^{\star}$} & \multicolumn{2}{|l|}{ Stage determinants } \\
\hline & & $A+B$ & $C$ & $D$ & $n a$ & $\begin{array}{l}12 \text { or more nodes } \\
\text { examined } \neq\end{array}$ & $\begin{array}{l}\text { Liver imaging } \\
\text { performed }\end{array}$ \\
\hline Varese (445) & 49 & 50 & 17 & 27 & 6 & 21 & 80 \\
\hline Modena (306) & 59 & 48 & 24 & 17 & 11 & 11 & 86 \\
\hline Calvados (262) & 53 & 45 & 20 & 24 & 11 & 23 & 77 \\
\hline Somme (228) & 50 & 43 & 19 & 21 & 17 & 4 & 63 \\
\hline Côte d'Or (237) & 50 & 57 & 25 & 14 & 4 & 20 & 82 \\
\hline Rotterdam (202) & 48 & 58 & 20 & 15 & 6 & 2 & 59 \\
\hline Eindhoven (256) & 55 & 55 & 19 & 21 & 5 & 5 & 59 \\
\hline Granada (173) & 46 & 41 & 23 & 19 & 17 & 31 & 49 \\
\hline Mersey (207) & 44 & 40 & 23 & 23 & 14 & 15 & 57 \\
\hline Thames (176) & 38 & 42 & 24 & 23 & 11 & 10 & 45 \\
\hline Cracow (228) & 25 & 21 & 18 & 21 & 39 & 10 & 44 \\
\hline All registries $(2720)$ & 48 & 46 & 21 & 21 & 13 & 14 & 67 \\
\hline$\% 3$ y survival & 48 & 73 & 45 & 11 & 26 & & \\
\hline Highest $†$ & 59 & 85 & 55 & 25 & 54 & & \\
\hline Lowest† & 25 & 56 & 28 & 6 & 8 & & \\
\hline RR of death (lowest $v$ highest) & 2.6 & 3.6 & 2.1 & 2.0 & 4.1 & & \\
\hline
\end{tabular}

${ }^{\star} \mathrm{A}+\mathrm{B}$, confined to the bowel wall; $\mathrm{C}$, lymph nodes involved; $\mathrm{D}$, distant metastasis; na, not available. ‡On "resected" patients

†Highest and lowest survival by registry. 
Table 3 Three year observed survival (\%) by Dukes'stage and registry, with percentages of resected cases in parentheses. EUROCARE high resolution study on colorectal cancer

\begin{tabular}{|c|c|c|c|c|c|}
\hline \multirow[b]{2}{*}{ Registry (No of cases) } & \multirow[b]{2}{*}{ All } & \multicolumn{4}{|c|}{ Dukes'stage * } \\
\hline & & $A+B$ & $C$ & $D$ & $n a$ \\
\hline Varese (445) & 49 & $71(98)$ & $55(97)$ & $8(54)$ & $37(36)$ \\
\hline Modena (306) & 59 & $82(100)$ & $53(99)$ & $25(72)$ & $31(34)$ \\
\hline Calvados (262) & 53 & $85(99)$ & $49(100)$ & $7(73)$ & $37(36)$ \\
\hline Somme (228) & 50 & $81(100)$ & $29(98)$ & $17(75)$ & $34(37)$ \\
\hline Côte d'Or (237) & 50 & $69(100)$ & $40(100)$ & $6(71)$ & $11(22)$ \\
\hline Rotterdam (202) & 48 & $63(100)$ & $48(98)$ & $10(52)$ & $8(0)$ \\
\hline Eindhoven (256) & 55 & $71(99)$ & $54(98)$ & $17(76)$ & $54(62)$ \\
\hline Granada (173) & 46 & $70(99)$ & $54(100)$ & $7(52)$ & $19(24)$ \\
\hline Mersey (207) & 44 & $78(100)$ & $48(100)$ & $6(60)$ & $23(53)$ \\
\hline Thames (176) & 38 & $61(96)$ & $30(98)$ & $10(59)$ & $32(32)$ \\
\hline Cracow (228) & 25 & $56(96)$ & $28(91)$ & $8(19)$ & $14(30)$ \\
\hline All registries (2720) & 48 & $73(99)$ & $45(98)$ & $11(60)$ & $26(34)$ \\
\hline
\end{tabular}

${ }^{\star} \mathrm{A}+\mathrm{B}$, confined to the bowel wall; $\mathrm{C}$, lymph nodes involved; $\mathrm{D}$, distant metastasis; na, not available.

of relative survival rates were both carried out to check the proportional hazard analysis; these results are mentioned in the discussion. The relative excess risks of dying (presented by stage in table 2) were calculated as the ratio of the logarithm of the lowest survival to the highest.

\section{Results}

Table 2 shows the overall three year observed survival by registry and the distribution and survival by Dukes' stage. Survival three years after diagnosis was poor in Cracow (25\%) followed by the Thames area (38\%), and relatively high in Modena (59\%), Eindhoven $(55 \%)$, and Calvados (53\%). Variation between registries was slightly greater for the older (more than 75 years) compared with the younger (less than 75 years) age groups, but for neither of these two age classes considered alone did the survival rank of the registries change compared with all ages considered together (not shown). The proportion of patients with a lesion confined to the bowel wall (that is, Dukes' stages A and B) was high in the Dutch registries and Côte d'Or, fairly high in the Italian registries, intermediate in Granada and in the English registries, and lowest in Cracow. Varese had the highest proportion of cases with distant metastases (Dukes' D) followed by Calvados and the English regis- tries. Cracow had the highest proportion of cases for which no information on stage could be found (39\%); most of the unresected cases in this registry had no staging information (63 of 108).

Three year observed survival for all cases combined was $73 \%$ for Dukes' stages A and B combined, $45 \%$ for Dukes' C, $11 \%$ for Dukes' $\mathrm{D}$, and $26 \%$ for cases with no staging information. Variation in survival between registries was larger for patients with localised lesions (about threefold) than for patients with distant metastases (twofold) (table 2, for a detailed description of survival by stage and by registry see table 3 ). Table 2 also provides information on the diagnostic determinants of stage considered in the study: liver imaging and number of nodes examined by the pathologist. The registries with the highest proportion of patients with 12 or more examined nodes were Granada (31\%), Calvados (23\%), Varese $(21 \%)$, and Côte d'Or $(20 \%)$; those with the lowest percentages were the Thames region, Cracow, and the Dutch registries. Liver imaging was performed in greater than $80 \%$ of patients in Modena, Côte d'Or, and Varese and in less than $50 \%$ in Granada, Thames, and Cracow.

Table 4 shows the three year observed survival for resected and unresected patients according to the definition we adopted. Survival for resected patients varied less between registries than survival for all patients (see table 2) but the rank order of the registries did not change: the maximum was $64 \%$ (Modena) and the minimum 39\% (Cracow). For unresected patients, inter-registry survival patterns changed. The poorest survival was for cases from Côte d'Or and the English areas, while survival of unresected patients in Cracow was close to the overall average for that registry. Table 4 also shows the proportions of patients who underwent surgical resection or palliative surgery, whether or not it was elective (not emergency), and the proportion of deaths within one month of diagnosis for all cases and for resected cases alone. In Cracow, 53\% and $29 \%$ of patients received surgical resection and

Table 4 Three year observed survival (3 y observed surv) for colorectal cancer by surgery and registry with distribution of cases by type of surgery, and deaths within one month of diagnosis. EUROCARE high resolution study on colorectal cancer

\begin{tabular}{|c|c|c|c|c|c|c|c|}
\hline \multirow[b]{3}{*}{ Registry } & & & \multicolumn{5}{|c|}{$\%$ Distribution of } \\
\hline & \multicolumn{2}{|c|}{3 y observed surv (\%) } & \multirow[b]{2}{*}{$\begin{array}{l}\text { Surgical } \\
\text { resection }\end{array}$} & \multirow[b]{2}{*}{$\begin{array}{l}\text { Palliative } \\
\text { surgery }\end{array}$} & \multirow[b]{2}{*}{$\begin{array}{l}\text { Elective } \\
\text { surgery }\end{array}$} & \multicolumn{2}{|c|}{ Death within 1 month } \\
\hline & $\begin{array}{l}\text { Resected } \\
(2241)\end{array}$ & $\begin{array}{l}\text { Unresected } t \\
(479)\end{array}$ & & & & $\begin{array}{l}\% \text { of all } \\
\text { cases }\end{array}$ & $\begin{array}{l}\text { \% of } \\
\text { "resected" cases }\end{array}$ \\
\hline Varese & 58 & 9 & 82 & 10 & 85 & 5 & 3 \\
\hline Modena & 64 & 25 & 88 & 5 & 84 & 2 & 2 \\
\hline Calvados & 61 & 8 & 85 & 3 & 84 & 6 & 2 \\
\hline Somme & 59 & 5 & 84 & 5 & 77 & 6 & 3 \\
\hline Côte d'Or & 54 & 0 & 93 & 3 & 87 & 6 & 5 \\
\hline Rotterdam & 54 & 13 & 86 & 7 & na & na & na \\
\hline Eindhoven & 59 & 15 & 92 & 2 & 77 & 3 & 3 \\
\hline Granada & 57 & 7 & 77 & 5 & 78 & 9 & 5 \\
\hline Mersey & 53 & 3 & 82 & 8 & 88 & 9 & 4 \\
\hline Thames & 47 & 3 & 79 & 7 & 85 & 16 & 5 \\
\hline Cracow & 39 & 9 & 53 & 29 & 56 & 16 & 8 \\
\hline All registries & 57 & 7 & 82 & 8 & 81 & 7 & 4 \\
\hline
\end{tabular}

†ncludes patients who underwent palliative surgery (211 cases) and those with no information on whether or not surgery was performed (32 cases).

*As a proportion of patients who underwent surgery.

na, not available. 
Table 5 Relative risk of death three years from diagnosis by registry, sex, age, site, stage, and determinants of stage (Cox model). EUROCARE high resolution study on colorectal cancer

\begin{tabular}{|c|c|c|c|c|c|c|}
\hline \multirow[b]{2}{*}{ Variable } & \multirow[b]{2}{*}{$\begin{array}{l}\text { Model } 1 \\
(\text { sex }+ \text { age }+ \text { site })\end{array}$} & \multirow[b]{2}{*}{$\begin{array}{l}\text { Model } 2 \\
\text { (model } 1+\text { stage) }\end{array}$} & \multicolumn{2}{|c|}{$\begin{array}{l}\text { Model } 3 \\
\text { (model } 2+\text { surgery }{ }^{*} \text { registry) }\end{array}$} & \multicolumn{2}{|c|}{$\begin{array}{l}\text { Model } 4 \\
(\text { model } 3+\text { determinants of stage } \\
\star \star\end{array}$} \\
\hline & & & Resected & $\begin{array}{l}\text { Non-resected } v \\
\text { resected }\end{array}$ & Resected & $\begin{array}{l}\text { Non-resected } v \\
\text { resected }\end{array}$ \\
\hline \multicolumn{7}{|l|}{ Registry (No of cases) } \\
\hline Varese (445) & 1 & 1 & 1 & $1.87^{\star}$ & 1 & $1.64^{\star}$ \\
\hline Modena (306) & $0.73^{\star}$ & $0.76^{\star}$ & 0.80 & $1.64^{\star}$ & 0.78 & $1.51^{\star}$ \\
\hline Calvados (262) & 0.91 & 0.95 & 0.91 & $3.00^{\star}$ & 0.90 & $2.69^{\star}$ \\
\hline Somme (228) & 0.96 & 0.94 & 0.91 & $3.19^{\star}$ & 0.83 & $3.08^{\star}$ \\
\hline Côte d'Or (237) & 0.93 & 1.21 & 1.19 & $3.67^{\star}$ & 1.20 & $3.22^{\star}$ \\
\hline Rotterdam (202) & 0.97 & 1.22 & 1.24 & $1.60^{\star}$ & 1.12 & $1.54^{\star}$ \\
\hline Eindhoven (256) & 0.85 & 0.95 & 1.00 & $1.99^{\star}$ & 0.92 & $1.87^{\star}$ \\
\hline Granada (173) & 1.24 & $1.26^{\star}$ & 1.09 & $3.51^{\star}$ & 1.11 & $2.78^{\star}$ \\
\hline Mersey (207) & 1.15 & 1.10 & 1.01 & $4.19^{\star}$ & 0.99 & $3.97^{\star}$ \\
\hline Thames (176) & $1.41^{\star}$ & $1.37^{\star}$ & 1.25 & $3.82^{\star}$ & 1.19 & $3.73^{\star}$ \\
\hline Cracow (228) & $2.32^{\star}$ & $1.81^{\star}$ & $1.82^{\star}$ & $1.57^{\star}$ & $1.69^{\star}$ & $1.57^{\star}$ \\
\hline \multicolumn{7}{|l|}{ Sex } \\
\hline Men (1391) & 1 & 1 & 1 & & 1 & \\
\hline Women (1329) & 0.96 & 0.99 & 1.00 & & 1.01 & \\
\hline \multicolumn{7}{|l|}{ Age $(y)$} \\
\hline $0-64(912)$ & 1 & 1 & 1 & & 1 & \\
\hline $65-74(807)$ & $1.28^{\star}$ & $1.37^{\star}$ & $1.36^{\star}$ & & $1.35^{\star}$ & \\
\hline $75+(1001)$ & $1.89^{\star}$ & $2.03^{\star}$ & $1.87^{\star}$ & & $1.86^{\star}$ & \\
\hline \multicolumn{7}{|l|}{ Site } \\
\hline Colon (1644) & 1 & 1 & 1 & & 1 & \\
\hline Rectum (1076) & $0.88^{\star}$ & 0.92 & $0.86^{\star}$ & & $0.85^{\star}$ & \\
\hline \multicolumn{7}{|l|}{ Stage } \\
\hline Dukes’ A+B (1242) & & 1 & 1 & & 1 & \\
\hline Dukes' C (N+)(562) & & $2.33^{\star}$ & $2.36^{\star}$ & & $2.47^{\star}$ & \\
\hline Dukes' D $(M+)(571)$ & & $7.55^{\star}$ & $5.86^{\star}$ & & $5.96^{\star}$ & \\
\hline Not available (345) & & $4.17^{\star}$ & $2.51^{\star}$ & & $2.44^{\star}$ & \\
\hline \multicolumn{7}{|l|}{ Examined nodes } \\
\hline $\begin{array}{l}\text { Not examined or not } \\
\text { available (1167) }\end{array}$ & & & & & 1 & \\
\hline $1-5(637)$ & & & & & 0.96 & \\
\hline $6-11(545)$ & & & & & $0.80^{\star}$ & \\
\hline $12+(319)$ & & & & & $0.68^{\star}$ & \\
\hline Missing, but examined (54) & & & & & 0.97 & \\
\hline \multicolumn{7}{|l|}{ Liver imaging } \\
\hline Yes (1816) & & & & & 1 & \\
\hline No (906) & & & & & 1.05 & \\
\hline
\end{tabular}

palliative surgery, respectively. In the English areas, Granada, and Varese approximately $80 \%$ of patients received surgical resection compared with more than $85 \%$ in the Dutch registry areas, Modena, and the French areas. Elective surgery was performed in only $56 \%$ of Cracow cases; for the other registries elective surgery varied from $87 \%$ (Côte d'Or) to $77 \%$ (Somme and Eindhoven). Sixteen per cent of all cases died within one month of diagnosis in the Thames region and Cracow, but among "resected" cases alone, this proportion was much lower ( $5 \%$ and $8 \%$, respectively). In Granada and Côte d'Or, 5\% of resected patients died within one month of diagnosis; for the Italian registries, Eindhoven, Somme, and Calvados values were lower. The proportion of resected cases by Dukes' stage and registry is given in table 3 .

Table 5 shows the relative risks (RRs) of death three years after diagnosis, by registry, as determined using the Cox proportional hazard method. The reference category was Varese which had the highest number of cases in the study. RRs are presented according to four different models. For the simplest model-that adjusted by age, sex, and primary site (colon or rectum)-RRs for Thames and Cracow were significantly higher, and the RR for Modena was significantly lower than that for Varese. After further adjusting by stage (model 2), the majority of RRs increased, except for those for
Cracow and the English registries which decreased. The RR for Cracow reduced because it had the lowest proportion of localised cases and the highest proportion of unstaged cases (the latter are likely to include many advanced unresectable cases). $R R$ values for the English registries were also reduced, compared with model 1 , because of unfavourable stage distribution (low proportion of localised and high proportion of metastatic cases). In contrast, RRs for Rotterdam and Côte d'Or increased considerably in model 2 as these registries had the most favourable distribution of stage (high proportion of localised and low proportion of metastatic cases).

Model 3 included the interaction of surgical treatment with registry. This interaction proved to be statistically significant. Thus the univariate survival analysis (table 4) revealed different patterns of death risk in resected and unresected patients across registries. Using model 3, the range of RRs between registries narrowed for patients who received surgical resection and only one registry differed significantly from Varese (Cracow with an RR of 1.82). RRs for patients that did not receive resection compared those who did are also given in table 5: these values show that in the two English registries the risk of death was about four times greater in unresected than resected patients, while in the Italian, Dutch, 
and Cracow registries, corresponding RRs were much lower.

Model 4 included the number of pathologically examined lymph nodes and liver imaging - factors considered as determinants of stage. For resected patients, this further adjustment lowered the RRs in Somme, Rotterdam, Eindhoven, Thames, and Cracow. The RR for Cracow, however, remained significantly higher than that for Varese. The $\mathrm{RR}$ for Côte d'Or remained slightly higher than that for Varese but did not differ significantly from it or from the other French registries. Note that the proportion of cases with 12 or more nodes examined was low in Somme (4\%), Rotterdam (2\%), Eindhoven (5\%), Thames, and Cracow (both 10\%) (table 2). Note also that the frequency of liver imaging examinations was lowest in the Thames area $(45 \%)$ and Cracow (44\%) and fairly low in Somme, Rotterdam, and Eindhoven. These data imply that on average, patients classified at a given stage in these areas had more advanced disease than patients classified at the same stage in other areas because they received less exhaustive staging investigations: this is a key finding of our study and explains why RRs were reduced in this model when these determinants of stage were included in the analysis, compared with model 3 .

Table 5 also shows the prognostic roles of site, sex, age, stage, and determinants of stage when included in the Cox analysis. The prognostic roles of age did not change when adjusted for stage and stage determinants. Risk of death increased significantly with age both before and after adjustment for stage and stage determinants. The risk of death at three years was slightly but significantly lower for patients with rectal than colon cancer. Survival was much lower in patients with more advanced disease. RRs for metastatic and unstaged cases decreased when surgery was included in the model. It was found that the relative risk of death decreased with increase in the number of nodes examined, the reason being that the number of nodes examined is a determinant of stage accuracy. The number of nodes examined is in fact the major determinant of stage migration of $\mathrm{N}+$ cases from Dukes' $\mathrm{A}+\mathrm{B}$ to Dukes' C: we found that the non-adjusted survival in resected patients with the localised stage (Dukes' A+B) and more than six nodes examined was higher than the same group with less than six nodes examined $(79 \% v 70 \%$ at three years). This is because Dukes' $A+B$ patients with fewer than six nodes examined will also include some at Dukes' C.

\section{Discussion}

For the 11 European populations considered in this study, survival three years after diagnosis varied from greater than 50\% (Modena, Eindhoven, and the French registries) to less than $40 \%$ for the Thames area in the UK (39\%) and Cracow (25\%). In Cracow only $53 \%$ of patients were resected and only $21 \%$ of patients had a lesion limited to the bowel wall. In the Thames region, the proportion of surgically treated patients was also lower than elsewhere
$(79 \%)$ as was the percentage of cases with Dukes' stages A and B (42\%). Considering only resected patients, as previously defined, survival differences between registries persisted but were smaller, although for Thames and Cracow three year survival was still less than $50 \%$.

After appropriate correction for stage, significantly poorer survival still characterised patients in Cracow, suggesting that they received less effective treatment than the average, whereas in the Thames region, survival became similar to other western European registries suggesting that the main reason for the low survival in the Thames area was late stage diagnosis. Better survival persisted in Modena after adjustment for stage and stage determinants, although the difference between other populations was no longer significant. In a recent study on regional differences in cancer survival in Italy, Modena was characterised by better survival for several cancers, ${ }^{11}$ which may be due to better medical care in this area of Italy.

To examine the quality of the basic data on which the survival analyses were performed, we assessed, for each registry, how completely incident cases had been reported, and how representative the analysed cases were of the total cases. The latter was achieved by comparison of mean age and survival of the cases provided by the registries for this study with corresponding values in the EUROCARE study (period of diagnosis 1985-1989). ${ }^{1}$ The mean age of cases did not differ between the two databases for each registry. For the three year observed survival, Cracow, Thames, Eindhoven, Varese, and the French registries had survival values in previous years $(22,40,51$, $50,47,45$ and $50 \%$, respectively) close to those in the present study (table 2). Whereas Modena (59 $v 47 \%$ ) and Mersey (44 $v$ 37\%) had higher, Rotterdam (48 $v 56 \%$ ) had lower survival figures than in previous years. For Modena, however, the present analysis was confined to cases in the town itself, while the previous analysis included the whole province. The differences for Mersey and Rotterdam are compatible with random variation.

Survival in this study was reported as observed survival - that is, regardless of the actual cause of death. We did this because of the short follow up period during which mortality from competing causes was expected to have a small influence on the results. To examine this, we calculated the three year relative survival for each registry. The maximum difference between observed (table 2, rounded figures given) and relative survival was found for Cracow $(24.7 \%$ v 26.5\%) and the minimum difference for Modena (59.4\% v 60.8\%). Therefore, in this three year study, competitive mortality did not change the ranking of registries for survival.

The proportional hazard model used for multiple regression analysis presented in table 5 assumes that relative risks are constant between each pair of covariates during the follow up period considered. This assumption may not be correct for long term survival data 
but is not expected to play a major role in the present case. As the purpose of this paper was mainly to analyse regional differences in survival across Europe, we also analysed survival using a different model that was stratified by registry and included sex, age, site, stage, and resection. The behaviour of registry specific survival rates obtained from this model three years after diagnosis was similar to the pattern of relative risks obtain by the Cox multivariate model shown in table 5. As expected, we found that the patterns of survival by age and stage in this second model were nonproportional but this did not affect the survival rank of the registries.

We found a significant interaction between surgery and registry, and this may indicate differences between registries in terms of the efficacy of surgery, quality of palliative care, or both. However, the variable proportion of resected cases among Dukes' D patients (see table 3) also suggests differences in approach to patients in different countries and areas. For example, the very high resection rate and fairly high mortality in the first month after diagnosis, with zero survival at three years for unresected patients in Côte d'Or, suggests that the prevalent approach is to operate whenever there is a chance that the patient can survive the operation. This contrasts with the pattern found in the Thames region where the resection rate was low, survival was low, and the overall mortality within one month was very high, which indicates that patients were generally diagnosed at a very late stage. In addition, in Cracow, the very low resection rate, high proportion of patients operated on in emergency, and the high proportion of deaths in the first month for both resected and unresected cases reflects very advanced stage at diagnosis for the majority of patients.

In the previous EUROCARE study on colon cancer for the period $1978-1985,{ }^{3}$ we found that survival differences between populations were largely confined to the first six months after diagnosis, and suggested that stage at presentation was the main factor responsible for the differences. The present study has provided direct evidence that disease stage at diagnosis is indeed the major determinant of survival differences between populations for most of Europe. In particular, we have now found that considerably more patients who died within the first six months had distant metastases than those who survived six months or more $(45 \% \quad v 11 \%)$; furthermore, the proportion of patients with distant metastasis or who were unstaged correlated directly with the proportion who died within the first six months (Pearson's $r=0.78, \mathrm{p}=0.005$ ).

As noted, the difference in survival between the English and European CRs narrowed when only resected patients were considered. A similar phenomenon was described by Prior and colleagues $^{12}$ in their analysis of colon cancer survival in an English registry compared with Europe. They found that exclusion of cases with only a clinical diagnosis produced survival estimates close to those of the European cohort. They considered that "clinically diag- nosed" (as opposed to histologically diagnosed) patients were accurately represented in the English registry but "lost" by all European registries because of less stringent registering practices in the whole of Europe; these clinically diagnosed cases contained a high proportion of late stage cancers with poor prognoses. The only evidence they cited for the assumption of a greater proportion of lost cases in Europe was that their model brought English survival up to the European level! In fact, there is no evidence to suggest that this is the case: indeed, the proportion of unstaged ("clinically diagnosed") patients was high in the English registries but was also high in the Spanish and French registries, in Modena and Cracow (see table 2 ).

In conclusion, our analysis of population based survival in this "cross section" of European colorectal cancer patients made use, for the first time, of clinical data specifically collected for the purpose by the registries and recorded in a standardised way using agreed protocols. We found that across Europe survival differences were large, but narrowed when corrections for stage were applied. Nevertheless, significant differences persisted, and in particular, survival remained low in Cracow. The large differences in survival of unresected patients most likely reflects different therapeutic approaches to patients with little chance of being cured. We suggest that much more attention should be paid to the early detection of colorectal cancer to improve the effectiveness of treatment and thus survival of patients who develop these cancers.

The EUROCARE study was financed through the BIOMED programme of the European Community. The authors are grateful to Donald Ward and Emily Taussig for editorial assistance. They are also indebted to Maria Rosa Ruzza for help in the quality control of the data.

1 Berrino F, Capocaccia R, Estève J, et al. Survival of cancer patients in Europe: the EUROCARE Study II. IARC patients in Europe: the EUROCARE Study II. IARC Scientific Publication No 151.

2 Gatta G, Sant M, Coebergh JW, Hakulinen T. Substantial variation in therapy for colorectal cancer across Europe: EUROCARE analysis of cancer registry data for 1987. Eur f Cancer 1996;32A:831-5.

3 Sant M, Capocaccia R, Verdecchia A, et al. Comparisons of colon-cancer survival among European countries: the EUROCARE study. Int $\mathcal{F}$ Cancer 1995;63:43-8.

4 Gatta G, Faivre J, Capocaccia R, Ponz de Leon $M$ and the EUROCARE Working Group. Survival of colorectal cancer patients in Europe during the period 1978-89. Eur 7 Cancer 1998;34:2176-83.

5 Feinstein AR, Sosin DM, Wells CK. The Will Rogers phenomenon: stage migration and new diagnostic techniques as a source of misleading statistics for survival in niques as a source of misleading statistics
cancer. New Engl f Med 1985;312:1604-8.

6 Hermanek P, LH Sobin, eds. TNM classification of malignant Hermanek P, LH Sobin, eds. TNM classification of malignant
tumours, 4 th edn, 2nd rev. UICC, International Union tumours, 4th edn, 2nd rev. UICC, Internation

7 Fielding LP, Arsenault PA, Chapuis PH, et al. ClinicopathoFielding LP, Arsenault PA, Chapuis $\mathrm{PH}$, et al. Clinicopatho-
logical staging for colorectal cancer: An International Documentation System (IDS) and an International Comprehensive Anatomical Terminology (ICAT). 7 Gastroenterol Hepatol 1991;6:325-44.

8 Berrino F, Estève J, Coleman MP. Basic issues in estimating and comparing the survival of cancer patients. In: Berrino F, Sant M, Verdecchia A, Capocaccia R, Hakulinen T, Estève J, eds. Survival of cancer patients in Europe. The EUROCARE Study. IARC Scientific Publication No 132. Lyon: International Agency for Research on Cancer, 1995.

9 Lee E T. Statistical methods for survival data analysis. New York: John Wiley and Sons, 1992.

10 Cox D. Regression models and life tables. $\mathcal{F} R$ Stat Soc B 1972;34:187-220.

11 Gatta G, Buiatti E, Conti E, et al. Variations in the survival of adult cancer patients in Italy. Tumori 1997;83:497-504.

12 Prior P, Woodman CBJ, Collins S. International differences in survival from cancer: more effective care versus less complete cancer registration. Br F Surg 1998;85:101-4. 